1 Universidade Federal da Bahia (UFBA), Instituto de Saúde Coletiva (ISC), Programa de PósGraduação em Saúde Coletiva - Salvador (BA) Brasil.

silier@outlook.com

2 Universidade do Estado do Rio de Janeiro (Uerj), Faculdade de Serviço

Social, Programa de Pós-

Graduação em Serviço

Social - Rio de Janeiro (RJ),

Brasil.

majodu@gmail.com

\section{Surfando no controle: os lugares que os agentes comunitários ocupam na produção de saúde mental}

\author{
Surfing on control: the positions that community agents occupy in the \\ production of mental health
}

Silier Andrade Cardoso Borges $\mathbf{1}$, Marco José de Oliveira Duarte²

RESUMO Este artigo aborda os lugares que os agentes comunitários ocupam na produção de saúde mental, através de conceitos como sociedade de controle, sujeito da experiência e clínica peripatética. Propõe-se uma leitura de orientação cartográfica sobre a interface entre saúde mental e Agentes Comunitários de Saúde. Retomam-se os percursos da Reforma Psiquiátrica com o Programa de Agentes Comunitários de Saúde e a Estratégia Saúde da Família. Finaliza com a discussão sobre os lugares paradoxais ocupados entre o poder sanitário e o universo sociocultural do território nas práticas dos agentes, de modo a problematizar a observação de Lancetti, de que tais profissionais surfam no controle.

PALAVRAS-CHAVE Agentes Comunitários de Saúde. Saúde da família. Saúde mental.

ABSTRACT This article addresses the positions that community agents occupy in the production of mental health, through concepts such as control societies, subject of the experience and peripatetic clinic. It is proposed a cartographic orientation reading about the interface between mental health and Community Health Agents. The paths of the Psychiatric Reform are restored with the Program of Community Health Agents and the Family Health Strategy. It ends with the discussion about the paradoxical places occupied between the health power and the socio-cultural universe of the territory in the practices of the agents, in order to problematize the observation of Lancetti, that such professionals 'surf on the control'.

KEYWORDS Community Health Workers. Family health. Mental health. 


\section{Introdução}

A Estratégia Saúde da Família (ESF) possui hoje abrangência nacional e é resultado da expansão do Programa Saúde da Família (PSF). A Política Nacional de Atenção Básica (PNAB), aprovada pela Portaria $\mathrm{n}^{0} 2.488$, de 21 de outubro de 2011, define a Atenção Básica (AB) como conjunto de ações de saúde, desenvolvido no âmbito individual e coletivo, e abrange a promoção e a proteção à saúde, a prevenção de agravos, o diagnóstico, o tratamento, a reabilitação e a manutenção da saúde. As ações e os serviços da $A B$ são desenvolvidos em território delimitado, sob forma de trabalho em equipe; utilizam tecnologias de elevada complexidade e baixa densidade; e, em definição, orientam-se pelos princípios da universalidade, integralidade, cuidado, vínculo, humanização, equidade e participação social (BRASIL, 2006).

No que tange aos recursos humanos necessários, a PNAB prevê: a implantação da estratégia de Agentes Comunitários de Saúde (ACS) nas unidades como dispositivo de reordenamento da $\mathrm{AB}$, integrando a equipe multiprofissional; o cumprimento da carga horária de 40 horas semanais; a existência de um enfermeiro para até 30 ACS; a definição de microáreas sob a responsabilidade de cada ACS, atendendo até 750 pessoas; e a regulamentação do exercício da profissão pela Lei ${ }^{\circ}$ 10.507/2002 (BRASIL, 2006).

Os ACS são atores centrais na identificação, no acolhimento e na orientação das pessoas em situação de sofrimento mental, considerando as que residem na comunidade. O Ministério da Saúde (MS) aponta que a proximidade entre a ESF e a comunidade, mediada pelos ACS, facilita a identificação de pessoas em sofrimento e, portanto (e em tese), o desenvolvimento precoce de ações de cuidado à saúde mental.

Dentre as atribuições do ACS, estabelecidas pela PNAB, destacam-se o desenvolvimento de ações que busquem a integração entre a equipe de saúde e a comunidade, acompanhando indivíduos e grupos sociais; e a necessidade de estar em contato permanente com as famílias, desenvolvendo ações educativas, visando à promoção da saúde e à prevenção das doenças. Nunes et al. (2002) identificam a condição contraditória e bidirecional implicada na construção identitária desses profissionais de saúde, entre o sistema médico oficial e as necessidades sociais sentidas e vivenciadas pelas famílias (BRASIL, 2006).

Nesse sentido, o presente artigo dedica-se à tentativa de reconstrução, por meio de ensaio teórico, de algumas questões que surgem no entorno das ações em saúde mental desenvolvidas pelos ACS, e discuti-las através de algumas ferramentas conceituais, como 'sociedade de controle', 'biopolítica', 'trabalho', 'sujeito da experiência' e 'clínica peripatética', propostas por uma leitura de orientação cartográfica das práticas discursivas na produção de conhecimento científico sobre a interface saúde mental e ACS.

Compreende-se que a prática da investigação cartográfica diz respeito, fundamentalmente, às estratégias das formações de desejo no campo social, isto é, atenta-se às estratégias do desejo em qualquer fenômeno da existência humana a que se propõe investigar. Pouco importam as referências teóricas do cartógrafo, mas sim a compreensão de que teoria é cartografia, tecida conforme as paisagens que o cartógrafo acompanha (ROLNIK, 2011).

Inicialmente, o presente artigo retomará algumas das contribuições da Reforma Psiquiátrica brasileira, para a inclusão da saúde mental na ESF, bem como sua relação histórica com o Programa de Agentes Comunitários de Saúde (Pacs) e demais iniciativas pioneiras, sem a pretensão de esgotar este extenso tema. E será finalizado com a abertura de novos questionamentos, por meio da discussão sobre sofrimento, trabalho e os lugares paradoxais ocupados pelos agentes comunitários na produção da saúde mental, de modo a problematizar a observação de Lancetti (2014), de que os ACS 'surfam no controle'. 


\section{Trajetórias e interfaces da Reforma Psiquiátrica com a Estratégia Saúde da Família}

Desde a Oficina de Trabalho para Discussão do Plano Nacional de Inclusões das Ações de Saúde Mental na Atenção Básica, em março de 2001, que contou com a participação do Departamento de Atenção Básica e da Coordenação Geral de Saúde Mental do Ministério da Saúde, com base nas experiências de alguns municípios, que se discute a implementação de ações de saúde mental na AB.

Importante guia para a orientação de ações de saúde mental na $\mathrm{AB}$ é o 'Caderno de Atenção Básica em Saúde Mental'. Neste manual, o MS, através dos autores e de suas trajetórias profissionais e de militância, reitera que a saúde mental não está dissociada das condições gerais de saúde, cabendo à $\mathrm{AB}$ o desafio de acolher, intervir e exercer o cuidado em saúde mental. Não se trataria, contudo, da descrição sumária de novas técnicas, mas de amplo texto, que situa a ética do cuidado como dispositivo que dispara processos de subjetivação dos usuários e suas famílias. Neste aspecto, a ‘Casa dos 20’ é um estudo de caso exemplar, apresentado na referida publicação, que instiga as Equipes de Saúde da Família (EqSF) na elaboração de projetos terapêuticos singulares, fomentando agenciamentos sensíveis e possíveis diante de situações concretas de vulnerabilidade (BRASIL, 2013).

De todo modo, deve-se lembrar que tal publicação é fato recente, antecedido pela larga trajetória de disputas diversas no interior do movimento da Reforma Psiquiátrica brasileira e de seus desdobramentos extensivos aos campos normativo (instituição das políticas de saúde mental) e social (das formas de representar e de lidar com o louco, com suas dinâmicas internas e seu entorno familiar e sociocomunitário, bem como com o (re)conhecimento dos seus direitos de cidadania).

Hirdes (2009) aponta que a superação do modelo manicomial e as bases para o trabalho desenvolvido em território encontram ressonâncias no processo de formulação e implementação das políticas de saúde no Brasil, a partir da VIII Conferência Nacional de Saúde, em 1986 da I Conferência Nacional de Saúde Mental (CNSM), em 1987; da II CNSM, em 1992; da III CNSM, em 2001; e, acrescente-se, também, a IV CNSM, em 2010. A autora localiza na Conferência Regional para Reestruturação da Assistência Psiquiátrica, realizada em Caracas, em 1990, elemento relevante para mudanças nas políticas implementadas no âmbito do MS, considerando que, na ocasião, o Brasil foi signatário da Declaração de Caracas.

Contudo, Amarante (1998) identifica, desde o final da década de 1970, o surgimento do Movimento dos Trabalhadores em Saúde Mental (MTSM), responsável por dar início ao processo da Reforma Psiquiátrica brasileira e originado, em parte, pelo Centro Brasileiro de Estudos de Saúde (Cebes) e pelo Movimento de Renovação Médica (Reme). O MTSM foi responsável por denunciar os crimes de tortura, as fraudes e a negligência no modelo asilar durante o regime militar. É notório que foram alguns membros do MTSM, integrados aos postos de administração municipal e estadual, que criaram as condições necessárias para a organização das CNSM (AMARANTE, 1998).

Deve-se salientar, de todo modo, que não há consenso sobre o tempo e os atores responsáveis por desencadear o processo de Reforma Psiquiátrica brasileira. Como derivação de ampla mobilização de trabalhadores, usuários e familiares organizados em movimentos sociais ao longo da década de 1970, obtiveram-se as experiências exitosas alternativas ao claustro hegemônico e à lógica privatista. Dentre essas alternativas de cuidado à saúde mental, destacaram-se o Centro de Atenção Psicossocial (Caps) Luiz Cerqueira, em 1987, na cidade de São Paulo (SP); a intervenção na Casa de Saúde Anchieta; e a invenção dos Núcleos 
de Atenção Psicossocial (Naps), na cidade de Santos (SP), experiências produtoras de trocas intersubjetivas, que estabeleceram novos modos de cuidar em território por meio da substituição do modelo asilar, fomentando a posterior elaboração e implementação normativa da política brasileira de saúde mental, porém, sempre atravessados por descontinuidades nas políticas executadas.

Nesse sentido, é possível observar o papel ativo dos trabalhadores em saúde, dos militantes e de usuários e seus familiares, bem como das experiências pioneiras nacionais (como as equipes volantes de saúde mental implementadas no Programa de Saúde Mental do Projeto Qualis/PSF, articulando-se ao trabalho dos agentes comunitários e das EqSF) na construção da política de saúde mental (LANCETTI, 2013, 2014). No âmbito internacional, múltiplos vetores e experimentações também compuseram os princípios que guiam a Reforma Psiquiátrica brasileira: da Inglaterra, a comunidade terapêutica e a antipsiquiatria; da França, a psicoterapia institucional e a psiquiatria de setor; e da Itália, a psiquiatria democrática.

Pitta (2016) aponta como princípio da Reforma Psiquiátrica a reabilitação psicossocial, compreendida como ética da solidariedade, que objetiva o aumento da contratualidade afetiva de sujeitos com limitações em seus afazeres cotidianos, ampliando a autonomia da vida em comunidade por meio de práticas intersetoriais de saúde, previdência, cultura, lazer, escola, moradia e trabalho. Como observado pela autora, não há uniformidade na definição da reabilitação psicossocial, sendo tantas as definições quanto as práticas existentes.

No entanto, há autores (ALVERGA; DIMENSTEIN, 2006) que indicam possíveis limites desse conceito, pois, em tese, essa noção permaneceria na discussão sobre o resgate de uma consciência cidadã de sujeitos desprovidos de poder de contratualidade, enquanto o conceito de desinstitucionalização implicaria na desconstrução das relações de exclusão e de dominação constitutivos da sociedade capitalista. De todo modo, a despeito das eventuais divergências teóricas, e considerando a multiplicidade de referenciais que nortearam a Reforma Psiquiátrica brasileira, não parece plausível sustentar a dissociação da desinstitucionalização ao conceito de reabilitação psicossocial.

Segundo Nunes, Jucá e Valentim (2007), a Organização Mundial da Saúde (OMS) reconheceu, nas décadas de 1970 e 1980, a necessidade de retirar a exclusividade da saúde mental das mãos dos especialistas, preconizando a descentralização da atenção, a articulação dos serviços, a formação de cuidadores não especializados e o cuidado na comunidade. Tais ideias foram incorporadas pela militância da Reforma Psiquiátrica, nascida no contexto da Reforma Sanitária.

Cabe destacar os impasses experimentados no processo da Reforma Psiquiátrica no Brasil. De acordo com Hirdes (2009), falta homogeneidade no processo das reformas, e as práticas são executadas segundo os referenciais de cada técnico em saúde mental. Contudo, deve-se questionar até que ponto é desejável a homogeneidade, considerando, como mencionou a autora, que as práticas e seus princípios são orientados pelos contextos específicos de onde ocorrem.

Inspirado em experiências de prevenção e educação em saúde desenvolvidas em comunidades, o Pacs teve iniciada a sua implementação em 1991, sendo regulamentado em 1997, acompanhando a descentralização de recursos do Sistema Único de Saúde (SUS) e a mudança de paradigma do indivíduo à família. Para reorientar o modelo de atenção, o MS iniciou a implantação do PSF em 1993, formando as primeiras EqSF em 1994, mesclando o Pacs com a Saúde da Família.

No entanto, nessa fase inicial, se evidenciou como a saúde mental foi incorporada meramente como discussão secundária, negligenciada diante de demandas outras, tidas como mais relevantes, a exemplo da hipertensão, das diabetes e das endemias, bem 
como das ações de saúde bucal, saúde nutricional, assistência ao pré-natal e à saúde da criança e da mulher.

Portanto, permanecem como dificuldades para a implementação das ações de saúde mental na ESF a insuficiência da retaguarda dos serviços especializados em saúde mental, a falta de diálogo entre os serviços de saúde e a rede intersetorial, bem como a necessidade de uma rede de cuidados articulada, que compreenda o território como espaço de exercício de cidadania e contratualidade.

Consiste em estratégia potente a lógica do apoio matricial nas ações de saúde mental, onde a responsabilização compartilhada entre o Núcleo de Apoio à Saúde da Família (Nasf) e a EqSF possibilita o acolhimento das demandas pela equipe de referência e pelos recursos sociocomunitários, evitando, assim, a medicalização do sofrimento e a institucionalização da loucura.

Logo, cabe mencionar que não apenas serviços como os Caps são relevantes para o acompanhamento de pessoas em sofrimento mental, mas também a ESF, que, ao lado dos demais dispositivos que compõem a rede, pode desenvolver o trabalho em saúde mental na comunidade de maneira articulada, garantindo a integralidade da atenção.

Deve-se salientar a persistência de outros impasses inerentes à $\mathrm{AB}$ no Brasil, a exemplo da preservação do modelo de assistência centrada na figura do médico e orientada para a doença e não para o doente. Como estratégia possível de superação das dificuldades da inserção das ações de saúde mental na AB, Hirdes (2009) identifica como caminho possível a apropriação de conceitos, tais como a clínica ampliada, o trabalho em rede e a qualificação das equipes multiprofissionais, contribuindo para a reorientação do modelo assistencial e do olhar para as práticas em curso.

Observa-se que há abundância de produção científica sobre o papel, os sentidos e as ações exercidas pela ESF no escopo da saúde mental. No entanto, enquanto alguns autores se restringem a descrever e discutir as ações executadas por técnicos de nível superior, permanecem escassas as produções que se debruçam sobre tais práticas desempenhadas pelos ACS. Cabe questionar como sintomática essa lacuna na produção científica, considerando-se o não lugar que é destinado aos agentes comunitários nas equipes de saúde.

Os 'não lugares' permitem grande circulação de pessoas, coisas e imagens em um único espaço, mas também transformam o mundo em um espetáculo imagético, do qual ninguém faz verdadeiramente parte, fazendo de todos meros espectadores (SÁ, 2014). Segundo Augé (APUD SÁ, 2014), esses 'não lugares' tratam-se dos espaços que aceleram o tempo e instituem relações de solidão e de anonimato, ao mesmo tempo em que se constituem como espaços de circulação. Não são espaços determinados empiricamente, mas pela construção do olhar, de modo que o não lugar de uns (usuários, em uma sala de espera) seja o lugar de outros (funcionários da recepção).

\section{Surfando no controle: os lugares que os agentes comunitários ocupam na produção de saúde mental}

Para Lancetti (2014), a clínica peripatética se faz em trânsito, em ambiente desprotegido; sai do consultório e se sustenta na surpresa que é escutar e reunir a família. Trata-se, contudo, de uma relação de força ambígua por natureza: por um lado, o pertencimento à organização médica e, por outro, a força afetiva produzida pelo encontro, possibilitando a emergência da subjetividade. Tratase de um trabalho experiencial, que se define pelo paradoxo do poder sanitário, médico e policialesco, e, simultaneamente, pela potência de afetar e ser afetado.

Assim, o exercício de uma clínica antimanicomial considera as peculiaridades do sofrimento psíquico sem recair em efeitos de 
quadriculamento e serialização do sujeito tido como desviante, mas com a finalidade de promover novas formas de existir no mundo, em espaços coletivos abertos à alteridade (BORGES, 2015).

Nesse sentido, considerando que os ACS são, ao mesmo tempo, integrantes da comunidade e do serviço sanitário, na fronteira da biopolítica do Estado, e agentes de produção de subjetividade, de experiência, de trabalho vivo e de cidadania, Lancetti (2014) afirma que 'eles surfam no controle'. Esta clínica, prenhe de paradoxos, exige, para melhor compreendê-la, prévia apresentação sobre as ferramentas conceituais biopolítica, trabalho vivo e sociedade de controle.

Biopolítica consiste em uma tecnologia de poder observada por Foucault (1999), que se instaura na metade do séc. XVIII, na Europa. Enquanto o poder disciplinar avança sobre o indivíduo, a biopolítica se dirige às populações, i. e., à sua multiplicidade viva. Não é mais um poder individualizante, que se coloca aos indivíduos a serem vigiados e treinados, mas à gestão de processos vitais, como nascimento, morte e doença, tornados tanto objetos de saber, pela epidemiologia, quanto pela intervenção, por meio da proliferação de instituições de assistência, dos mecanismos de previdência e seguro-saúde, e pela medicalização do mundo social.

O trabalho vivo é

trabalho em ato e em criação, de controle do próprio trabalhador, [...] oferece altos graus de liberdade na execução de sua atividade produtiva, pois se realiza enquanto o produto é realizado. (FRANCO; MERHY, 2012, P. 154).

O trabalho em saúde é imaterial e centra-se no trabalho vivo e em seu potencial de autogestão. Contudo, ao trabalho podem-se suceder processos de captura, através da incorporação, pelo profissional de saúde, de práticas hegemônicas biomédicas, prescritivas e tecnoassistenciais, no processo produtivo, em substituição ao fazer afetivo e relacional do trabalho vivo (FRANCO; MERHY, 2012).

A sociedade de controle, fundante no projeto de modernidade, se efetiva na crise dos espaços tradicionais e disciplinares de confinamento (escolas, conventos, manicômios, prisões, família, fábrica). Para Deleuze (1992), o atendimento a domicílio pode marcar, de início, novas liberdades, mas também passa a integrar mecanismos de controle que rivalizam com os mais duros dos confinamentos. Se os confinamentos são moldes, os controles são modulações, e o controle contínuo substitui o exame. No âmbito da saúde, trata-se de uma medicina sem doentes e sem médico, sujeitos ao risco do adoecimento. Perspectiva semelhante foi apontada por Guattari e Rolnik (2011), em outra ocasião, quando abordaram os efeitos da capilarização dos serviços de saúde no território como resultado de uma estratégia micropolítica de controle sanitário. A discussão da sociedade de controle colocava a Deleuze a necessidade de abordar tais fenômenos como fluxos e processos (sobretudo, naquilo que Guattari chamava de processos de reapropriação de territórios subjetivos por uma produção de subjetividade industrial), de modo que o filósofo, deslocando as palavras para novos sentidos, afirmou que "por toda a parte, o surf já substituiu os antigos esportes" (DELEUZE, 1992, P. 223).

A contradição inerente ao trabalho do ACS, porta voz da comunidade e também o responsável pela divulgação da informação biomédica no território, fazendo parte da população ao mesmo tempo em que trabalha com ela, produz efeitos na organização do trabalho da equipe de saúde e na subjetividade desses agentes. É geralmente ao ACS que a população busca, em primeiro lugar, para realizar uma reclamação, solicitar uma informação ou buscar solução para problemas que exigem respostas. De outro lado, a EqSF espera do ACS aceitação pela comunidade local, facilidade de comunicação, integração à equipe e incorporação dos seus valores, capacidade de planejamento e execução de 
ações, identificação precoce de doenças de notificação compulsória, acompanhamento de grupos de risco, cobertura da área de abrangência etc. As expectativas de diferentes naturezas depositadas, quando não atendidas, podem se desdobrar em situações de sofrimento no trabalho (MARTINES; CHAVES, 2007). Por esta razão, considerando-se que o trabalho do agente pode envolver desgaste afetivo, não é raro que eles prefiram não realizar ações de cuidado à saúde mental no território em que atuam.

Dejours (2004) aponta que o trabalho não se reduz à relação empregatícia, mas implica tudo aquilo que envolve o ato de trabalhar: gesto, engajamento do corpo, saber-fazer, interpretar, sentir, reagir, inventar etc. Portanto, o trabalho é corporificado, experiência que só se exerce no mundo. Diante da impossibilidade de exercício do trabalho, caso as prescrições e regras sejam seguidas à risca, e tendo-se em vista que o trabalho sempre comporta algo de inusitado e de imprevisto (panes, incidentes, inesperados nas relações com chefes, equipe, pacientes, subordinados, ferramentas, hierarquia etc.), o sofrimento se produz diante do distanciamento entre o trabalho prescrito, delimitado pelas regras e normas organizacionais, e o trabalho real que as situações interpõem. Se trabalhar é prescrever a lacuna entre o prescrito e o real, exige-se do trabalhador, a cada instante, a invenção diante da resistência do real, produzindo sentimentos de impotência e de fracasso.

Pelas razões explanadas, o trabalho nunca é neutro e é sempre afetivo. Martines e Chaves (2007) relatam sobre o sofrimento apresentado pelos ACS como resultado da desproporção entre o perfil esperado pela equipe e o perfil real do agente, e pelos esforços realizados para superar essa lacuna, tanto pelo agente quanto pela equipe e pela comunidade, expondo-o ao sofrimento no trabalho. Esta lacuna entre o real e o prescrito é identificada, no estudo de Rosa, Bonfanti e Carvalho (2012), pela perda da especificidade da profissão e pelo desvirtuamento de suas atribuições, ao lado das condições de insalubridade, das dificuldades na relação com a equipe e do intenso envolvimento emocional na relação com os usuários. Lopes et al. (2012), em seu estudo, reconhece semelhantes condições de sofrimento às quais esses profissionais estão expostos, dentre as quais se destacam o envolvimento com os problemas de ordem social da própria comunidade na qual residem e atuam, bem como o medo decorrente da exposição à violência. $\mathrm{O}$ trabalho do ACS é afetivo porque intervém, em ambiente aberto, desprotegido e a cada instante, no território existencial das pessoas (LANCETTI, 2010).

Esses aspectos, produtores do mal-estar sentido pelos ACS, são definidos da seguinte maneira:

É o ACS que entra em contato mais cruamente com as diversas formas de sofrimento da população. Seu papel ultrapassa, portanto, as atribuições que the competem, afinal a vida no bairro, em suas diversas expressões, continua depois do expediente, nos feriados e nos fins de semana. Assim, há que se considerar que, geralmente, a atuação do ACS está permeada de considerável envolvimento pessoal e interpessoal, o que pode trazer conflitos e desgaste emocional. (ROSA; BONFANTI; CARVALHO, 2012, P. 148-149)

Vivem-se tempos de destruição da experiência, seja pelo trabalho, seja pela falta de tempo ou pela popularização da opinião na era da fugacidade da informação. $\mathrm{O}$ sujeito moderno é o sujeito informado, que trabalha e opina, definido pelos seus artefatos técnicos e pela abundância de conhecimento objetivo. Diferentemente, o sujeito da experiência é um território de passagem onde se produzem efeitos sobre uma superfície sensível e encarnada, compreendido pela sua abertura, atenção ou receptividade. A experiência seria "o que nos passa, o que nos acontece, o que nos toca. A cada dia se passam muitas coisas, porém, quase nada nos acontece" (BONDÍA, 2002, P. 21). 
O trabalho na ESF convoca os técnicos a um fazer de complexidade invertida, posto que o trabalho hospitalar é menos complexo do que a práxis desenvolvida no território geográfico e existencial. Para Lancetti (2010), quanto mais se opera em território, mais complexos são os procedimentos, como acontece, por exemplo, em uma situação de negociação de sentidos entre equipe e usuário, sobre o sofrer. No caso da internação hospitalar, a simplificação da intervenção resulta em consequências nada simples: a atuação como bombeiro, que reproduz anacronismos e dependência institucional. É complexo porque, na feitura do Projeto Terapêutico Singular, há algo de singular, experiencial e coletivo. Também por conta da complexidade de suportar a crise sem recorrer ao manicômio e ao cárcere, mas ao saber da experiência que ativa recursos escondidos na própria comunidade. Bondía (2002, P. 26) afirma que:

Definir o sujeito da experiência como sujeito passional não significa pensá-lo como incapaz de conhecimento, de compromisso ou ação. A experiência funda também uma ordem epistemológica e uma ordem ética. O sujeito passional tem também sua própria força, e essa força se expressa produtivamente em forma de saber e em forma de práxis. $O$ que ocorre é que se trata de um saber distinto do saber científico e do saber da informação, e de uma práxis distinta daquela da técnica e do trabalho.

No território, mundos são fabricados na interlocução dos técnicos com os usuários dos serviços e seus universos culturais, não necessariamente 'adscritos' pelos programas e portarias. Aqui, território é compreendido como espaço de produção de vida e sentido produzido por pessoas em movimento, e em relação contratual, umas com as outras (LANCETTI, 2014).

Essa ambiguidade de papéis que se vem discutindo é experimentada pelos ACS por meio do lugar de 'tradutores' que assumem, de forma a transmitir conhecimentos e práticas biomédicas à comunidade, ressignificados pela mediação de um agente proveniente das camadas populares. Os ACS não apenas 'traduzem', mas efetuam conhecimentos híbridos de ordem técnico-científica, que se mesclam com o universo social, cultural e linguístico. Não é à toa que a PNAB preconiza que os agentes, em geral, trabalhem no território em que residem, porque as práticas sanitárias são maximizadas em eficácia pelo compartilhamento desse universo em comum por esse agente de mediação. Isto é, parte-se da premissa que o ACS possui a indispensável compreensão sobre as questões das necessidades e dos conflitos, por conta de sua pertença à comunidade.

Contudo, ressalta-se que não são escassos os relatos de atuações onde a complexidade das demandas em saúde suscitadas pela ação educativa foi apartada das histórias, das narrativas e dos saberes dos usuários dos serviços, resultando em fazeres e em discursos normatizadores, que objetivam a 'adesão aos estilos de vida e hábitos saudáveis', definidores de bons ou maus comportamentos (NUNES ET AL., 2002). Tratar-se-iam de práticas de controle que produzem verdades sobre os corpos e que suscitam a obediência de usuários sob a égide do discurso de 'promoção da saúde'.

A insuficiência dos serviços substitutivos, reduzidos aos horários administrativos, alheios às paisagens e às dinâmicas vitais da comunidade, ao mesmo tempo em que resultam em serviços não substitutivos, não raro se distancia das modulações de uma clínica peripatética, adequando-se aos interesses privatistas e à lógica do mercado da loucura, que reterritorializa esses vazios assistenciais por meio de instituições privadas, caritativas ou religiosas. Enquanto isso, a Reforma Psiquiátrica é reduzida a discussões sectárias, burocráticas ou demasiadamente reformistas, distanciando-se do seu potencial revolucionário (LANCETTI, 2004).

A radicalidade da Reforma Psiquiátrica 
não residiria na 'humanização dos serviços de saúde mental', pois há de se desconfiar das pretensões doutrinárias que podem se ocultar por trás desse conceito a serviço do biopoder: não se trataria de tornar bom e afável o manicômio, garantindo a sua continuidade perversa, mas de destruí-lo ou implodi-lo, para além de seus espaços físicos e de seus muros ideológicos. As práticas de saúde impõem, de fato, a todos os profissionais, e, de certo modo, colocam não apenas aos agentes comunitários, o paradoxo do trabalho da humanização como domesticação das pessoas e como afirmação da potência de vida na escuta e no alívio do sofrimento humano (LANCETTI, 2009).

É nesse contexto que a ESF emerge, como caminho concreto para a construção do SUS, nos dizeres de David Capistrano. E é nas trilhas deste caminho concreto, onde se efetiva o SUS, que surge o agente comunitário, não como frágil substituto dos serviços especializados e dos ambulatórios precarizados ou insuficientes, mas a partir do reconhecimento de que a reabilitação psicossocial é mais eficaz quando operada na $\mathrm{AB}$, feita no território onde as pessoas vivem (LANCETTI, 2004). Não se trataria de outorgar ao ACS a responsabilidade por todos os cuidados em saúde mental, mas de reorientar a organização dos serviços de saúde, de modo que médicos, odontólogos, enfermeiros, técnicos, recepcionistas, vigilantes, pessoal da limpeza, sejam todos, enfim, corresponsáveis pela produção de saúde mental.

\section{Conclusões}

O trabalho do ACS é permeado pela ambiguidade de papéis, pela necessidade de gerir o inusitado e de fazer engajar o corpo na construção de experiências afetivas como requisito da resolutividade de sua atuação. $\mathrm{O}$ seu fazer oscila entre a aridez das condições materiais de produção de saúde, as exigências institucionais e as expectativas comunitárias, convivendo com a inadequação entre a insalubridade do trabalho e o mal-estar que a tarefa cotidiana lhe impõe.

Simultaneamente, integrante do serviço sanitário, sujeito da informação e membro da comunidade, é quem compartilha o universo sociocultural do território, suas diferentes racionalidades e seus múltiplos modos de significar o processo saúde-doença, podendo tecer lugares de cuidado no espaço entre serviço e comunidade.

Não raro, por essas razões, o agente comunitário é também aquele que adoece, no interstício do trabalho prescrito e do trabalho real. Trata de realizar um trabalho marcado por contextos que também se definem por vazios assistenciais e pelo enfraquecimento dos serviços públicos na garantia de necessidades fundamentais, cada vez mais preenchidas por instituições privadas, religiosas, caritativas ou asilares. O exercício do ACS é entremeado de vínculos de trabalho fragilizados, por contextos de atuação insalubres e pelo desgaste afetivo resultante de relações de poder entre os agentes comunitários e os demais integrantes da EqSF, que nem sempre os reconhecem como profissionais imbuídos de tecnologia potente e produtora de saúde mental comunitária, reproduzindo relações verticalizadas e os destituindo do saber da experiência.

A potência do trabalho dos ACS não se localiza em seu papel formal de 'tradutores' do discurso técnico-científico à população passiva e receptora das práticas sanitárias, como preconizado no modelo de atenção campanhista, mas sim na produção de conhecimentos híbridos entre o científico e o sociocultural, ampliando a produção de vida e saúde por meio da interlocução de atores no território onde vivem as pessoas e as suas diferentes necessidades, individuais e coletivas.

O ACS, trabalhador afetivo e efetivo, que transita nas regiões de grande tensão das cidades e, enquanto tal, se insere no território existencial das comunidades e das famílias, é forjado enquanto sujeito pela e na experiência de sua prática, ao mesmo 
tempo clínica e política. Seriam 'os loucos e os drogados', como são assim entendidas as pessoas acompanhadas em seus diferentes modos de existir, o sujeito-objeto do medo social fundamental, que contribui para a manutenção do funcionamento do capitalismo, por meio da indissociável relação entre exclusão e inclusão. Este trabalho vivo do agente comunitário se faz por meio dessa clínica peripatética, que escuta e corporifica narrativas repletas de modulações, desafios, implicações, surpresas e transitoriedades.

Não havendo soluções prontas ou fórmulas mágicas para as inumeráveis demandas que o território impõe, compete ao agente comunitário, a cada surpresa que é o encontro, na sua práxis peripatética imbuída de trabalho vivo, desempenhado em rede junto à equipe de saúde da família, garantir acesso ao direito à saúde por meio da produção de modos singulares de cuidado nas realidades concretas do usuário dependente de drogas, da pessoa em situação de rua sem acesso a documento e abrigamento, do idoso vítima de negligência, do louco em cárcere privado, da senhora em situação de violência doméstica, daqueles que se encontram com seus vínculos familiares fragilizados ou rompidos.

No campo da saúde mental, seu trabalho afetivo, de um lado, transita entre a macropolítica da PNAB, da Lei Federal da Reforma
Psiquiátrica, da Rede de Atenção Psicossocial e de tantos outros marcos jurídico-legais, exigindo-lhe a assunção do papel de agente promotor do direito a uma existência digna, e de outro, enquanto agente produtor de vida na prática micropolítica do possível naquilo que o serviço de saúde e o território sociocomunitário lhe oferece como arsenal e como caixa de ferramentas.

O ACS surfa no controle porque, a todo tempo, para produzir saúde, se equilibra no jogo incerto entre o saber da experiência e o saber biomédico, em tempos de uma sociedade de controle.

\section{Colaboradores}

Ambos os autores participaram da concepção do artigo, contribuindo para a revisão crítica de seu conteúdo, e participaram da aprovação da versão final do artigo.

\section{Agradecimentos}

À Professora Dra Ana Maria Fernandes Pitta, pelas suas valiosas contribuições ao processo de aprendizagem necessário à redação deste manuscrito. 


\section{Referências}

ALVERGA, A. R.; DIMENSTEIN, M. A reforma psiquiátrica e os desafios na desinstitucionalização da loucura. Interface (Botucatu), Botucatu, v. 10, n. 20, p. 299-316, dez. 2006.

AMARANTE, P. Loucos pela vida: a trajetória da reforma psiquiátrica no Brasil. 2. ed. Rio de Janeiro: Fiocruz, 1998.

BONDÍA, J. L. Notas sobre a experiência e o saber da experiência. Revista Brasileira de Educação, Rio de Janeiro, p. 21-28, n. 19, 2002.

BORGES, S. A. C. Territórios existenciais ético-estéticos em saúde coletiva. Fractal, Rev. Psicol., Niterói, v. 27, n. 2, p. 107-113, ago. 2015.

BRASIL. Ministério da Saúde. Secretaria de Atenção à Saúde. Departamento de Atenção Básica. Política Nacional de Atenção Básica. Brasília, DF: Ministério da Saúde, 2006

Ministério da Saúde. Secretaria de Atenção à Saúde. Departamento de Atenção Básica. Saúde mental. Brasília, DF: Ministério da Saúde, 2013.

DEJOURS, C. Subjetividade, trabalho e ação. Prod., São Paulo, v. 14, n. 3, p. 27-34, dez. 2004.

DELEUZE, G. Conversações. São Paulo: Ed. 34, 1992.

FOUCAULT, M. Em defesa da sociedade: curso no Còllege de France (1975-1976). São Paulo: Martins Fontes, 1999

FRANCO, T. B.; MERHY, E. E. Cartografias do trabalho e cuidado em saúde. Revista Tempus Actas de Saúde Coletiva, Brasília, DF, v. 6, n. 2, p. 151-63, 2012.

GUATTARI, F.; ROLNIK, S. Micropolítica: cartografias do desejo. 11 ed. Petrópolis: Vozes, 2011.

HIRDES, A. A reforma psiquiátrica no Brasil: uma (re) visão. Ciência \& Saúde Coletiva, Rio de Janeiro, v. 14, n. 1, p. 297-305, fev. 2009.
LANCETTI, A. Clínica peripatética. 9. ed. São Paulo: Hucitec, 2014.

A formação como combate. In: LOBOSQUE, A. M. (Org.). Caderno Saúde Mental 3: saúde mental: os desafios da formação. Belo Horizonte: ESP-MG, 2010.

Notas sobre clínica e política. Revista

Latinoamericana de Psicopatologia Fundamental, São Paulo, v. 7, n. 3, p. 67-69, 2004.

Notas sobre humanização e biopoder. Interface (Botucatu), Botucatu, v. 13, supl. 1, p. 797-799, 2009.

Saúde mental nas entranhas da metrópole. In: LANCETTI, A. (Org.). Saúde Loucura 7: saúde mental e saúde da família. 3. ed. São Paulo: Hucitec, 2013.

LOPES, D. M. Q. et al. Agentes comunitários de saúde e as vivências de prazer - sofrimento no trabalho: estudo qualitativo. Rev. Esc. Enferm. USP, São Paulo, v. 46, n. 3, p. 633-640, jun. 2012.

MARTINES, W. R. V.; CHAVES, E. C. Vulnerabilidade e sofrimento no trabalho do agente comunitário de saúde no Programa de Saúde da Família. Rev. Esc. Enferm. USP, São Paulo, v. 41, n. 3, p. 426-433, set. 2007.

NUNES, M.; JUCA, V. J.; VALENTIM, C. P. B. Ações de saúde mental no Programa Saúde da Família: confluências e dissonâncias das práticas com os princípios das reformas psiquiátrica e sanitária. Cad. Saúde Pública, Rio de Janeiro, v. 23, n. 10, p. 2375-2384, out. 2007.

NUNES, M. O. et al. O agente comunitário de saúde: construção da identidade desse personagem híbrido e polifônico. Cad. Saúde Pública, Rio de Janeiro, v. 18, n. 6, p. 1639-1646, dez. 2002.

PITTA, A. M. F. Reabilitação psicossocial no Brasil. 4. ed. São Paulo: Hucitec, 2016.

ROLNIK, S. Cartografia sentimental: transformações contemporâneas do desejo. Porto Alegre: UFRGS, 2011. 
ROSA, A. J.; BONFANTI, A. L.; CARVALHO, C. S. O

sofrimento psíquico de agentes comunitários de saúde e suas relações com o trabalho. Saúde e Sociedade, São Paulo, v. 21, n. 1, p. 141-152, mar. 2012.

SÁ, T. Lugares e não lugares em Marc Augé. Tempo
Soc., São Paulo, v. 26, n. 2, p. 209-229, dez. 2014

Recebido para publicação em outubro de 2016

Versão final em julho de 2017

Conflito de interesses: inexistente

Suporte financeiro: não houve 